\title{
REVISION DE MULTAS DE LOS ALCALDES EN MATERIA URBANISTICA
}

$71: 343,271.352$

\author{
por \\ Luis Arce Monzón \\ Secretario general del Ayuntamiento de Oviedo. \\ Diplomado en Administración local
}

SUMARIO: I. PLANTEAMIENTO DEL PROBLEMA.-II. SANCIONES Y RECURSOS EN LA LEY DE 12 DE MAYO DE 1956.-III. SAN. CIONES DE MULTA Y RECURSOS EN LA LEY 19/1975, DE 2 DE MAYO, DE REFORMA DE LA LEY DEL SUELO.-IV. RECURSO DE ALZADA CONTRA LAS MULTAS IMPUESTAS POR LOS ALCALDES EN MATERIA URBANISTICA.-V. CONCLUSIONES.

\section{PLANTEAMIENTO DEL PROBLEMA}

El régimen de recursos respecto a los actos administrativos de las Entidades locales es un síntoma para juzgar el momento de mayor o menor vigencia y respeto a la autonomía local. En otras palabras, la utilización del recurso ordinario de alzada contra acuerdos o actos administrativos de las autoridades y Corporaciones locales significa un mayor control e intervención de los órganos de la Administración central. En definitiva, cuando surgen reformas de las leyes que afectan a la Vida local es preciso asomarse al capítulo de la revisión de los actos locales por vía del sistema de recursos, para comprobar si soplan vientos más o menos municipalistas y autonómicos. 
La Ley 19/1975, de 2 de mayo, de Reforma de la Ley sobre Régimen del Suelo y Ordenación urbana de 12 de mayo de 1956, nace cuando ésta se encontraba próxima a los veinte años de vida. El sistema político, con ser el mismo fundamentalmente, había experimentado una sensible evolución. Incluso en el transcurso de los diecinueve años entre una y otra Ley, se promulgaron dos Leyes Fundamentales del Reino: la Ley de Principios Fundamentales del Movimiento Nacional de 17 de mayo de 1958 y la Ley Orgánica del Estado de 10 de enero de 1967. Es más, el Régimen local se encontraba en fase de reforma, con sucesivos anteproyectos y proyectos, que culminarían, finalmente, en la Ley 41/1975, de 19 de noviembre, de Bases del Estatuto de Régimen local.

Este trabajo queremos centrarlo y concretarlo al problema de la revisión de los acuerdos o actos de los Organismos municipales en la Ley de Reforma de la del Suelo. Y, más en particular, limitado al régimen de recursos contra los actos sancionadores del Alcalde por infracciones urbanísticas. Veremos si se ha conseguido o no un progreso autonómico local en esta materia.

\section{SANCIONES Y RECURSOS EN LA LEY DE 12 DE MAYO DE 1956}

Recapitulemos los preceptos de la Ley de Régimen del Suelo y Ordenación urbana de 12 de mayo de 1956 sobre sanciones de los Alcaldes en materia de urbanismo:

a) Las infracciones urbanísticas serán sancionadas gubernativamente por los Alcaldes mediante la imposición de multas (artículo 215,1 ).

b) Los acuerdos municipales a que se refiere, entre otros, el artículo 215 , son susceptibles de recurso de alzada ante la Comisión Provincial de Urbanismo (artículo 220).

c) Pero, para complicarlo más, el infeliz artículo 217 establece que: "con anterioridad a la interposición de cualquiera de los recursos administrativos admisibles, será obligatorio deducir, ante la misma autoridad $u$ órgano que hubiera dictado el acuerdo, recurso de reposición». 
Así pues, frente al acto administrativo del Alcalde imponiendo sanción de multa, por una infracción urbanística, habría de interponerse un recurso de reposición ante el Alcalde, de carácter administrativo, de cierta peculiaridad, que no era el previo al contencioso-administrativo. Después, el recurso administrativo de alzada ante la Comisión Provincial de Urbanismo. La jurisprudencia del Tribunal Supremo, comprensiblemente, anduvo oscilante sobre la aplicación del famoso artículo 217, que obligaba a este extraño recorrido. No es el momento para tratar esta cuestión, hoy superada. Sin embargo, siempre opinamos que el juego del artículo $1 .^{\circ}, 3$, con el Título $\mathrm{V}$ de la Ley de Procedimiento administrativo de 17 de julio de 1958 , en relación con el número 36 del artículo $1 .^{\circ}$ del Decreto de 10 de octubre de 1958, nos conducía a la exclusión del pintoresco recurso de reposición establecido en el artículo 217 de la Ley del Suelo.

III. SANCIONES DE MULTA Y RECURSOS EN LA LEY 19/1975, DE 2 DE MAYO, DE REFORMA DE LA LEY DEL SUELO

La Exposición de Motivos de la Ley 19/1975 proclama solemnemente: «También se hace notar que el Proyecto, respetuoso en todo lo posible con el régimen jurídico propio de la actuación municipal, suprime los casos en los que se establecían recursos contra los acuerdos municipales ante la Administración del Estado. Todos los acuerdos de los Ayuntamientos serán impugnables directamente ante la Jurisdicción Contencioso-administrativa. Desaparecen, por tanto, los recursos de alzada ante las Comisiones Provinciales de Urbanismo o el Ministerio de la Vivienda".

En el texto de la Ley se contienen, consecuentemente con la Exposición de Motivos, estas disposiciones:

a) Las infracciones urbanísticas serán sancionadas con multas impuestas (entre otras autoridades) por los Alcaldes (artículo 215 bis).

b) Artículo 225.- «1. Los actos de las Entidades locales, cualquiera que sea su objeto, que pongan fin a la vía administrativa, serán recurribles directamente ante la Jurisdicción Contencioso-administrativa». 
El texto del transcrito artículo 225 merece estas afirmaciones y puntualizaciones:

a) Se ha suprimido el anterior recurso de alzada ante la Comisión Provincial de Urbanismo frente a las multas impuestas por los Alcaldes por infracciones urbanísticas.

b) Antes del recurso en la Jurisdicción Contencioso-administrativa contra los citados actos sancionadores de los Alcaldes, ha de interponerse el recurso previo de reposición ante dicha autoridad. Claramente lo expone GonZÁlez PÉREZ: «El reconocimiento de que son recurribles «directamente» ante la Jurisdicción no supone una exclusión del recurso de reposición, que será exigible como requisito previo, según la norma general del artículo 52 de la Jurisdicción Contencioso-administrativa. El precepto únicamente ha querido destacar la innecesariedad de recurso ante órganos del Estado» ( «La revisión de los actos de la Administración en materia urbanística», Revista de Derecho Urbanístico, núm. 46, enero-febrero 1976 , página 30).

Sin embargo, queda latente el problema central que nos preocupa y ocupa en este trabajo. Por aplicación de la Ley 19/1975 no cabe el recurso de alzada. Pero, ¿qué ocurre con la Ley de Régimen local? Aquí está la cuestión.

\section{RECURSO DE ALZADA CONTRA LAS MULTAS IMPUESTAS POR LOS ALCALDES EN MATERIA URBANISTICA}

Se reaviva, en nuestra opinión, el artículo 385 de la Ley de Régimen local, texto refundido de 24 de junio de 1955, conforme al cual: "Contra las multas impuestas por las autoridades locales, que no tengan señalado recurso especial, cabrá el recurso de alzada, en única instancia, ante el Gobernador civil en el término de diez días siguientes a la notificación del acuerdo o de la resolución expresa o tácita del recurso de reposición si fuese utilizado». Razones:

a) La generalidad del precepto contenido en el citado artículo 385 , que ha de entenderse referido no solamente a las multas por infracción de las Ordenanzas, Reglamentos y Bandos de policía y buen gobierno contempladas en los artículos 111 y 115 de la mis- 
ma Ley de Régimen local. El contexto de aquel artículo 385 "contra las multas impuestas por las autoridades locales» no permite una limitación a estas infracciones de los artículos 111 y 115 . En la repetida Ley de Régimen local se regulan otros supuestos de multas, como las que los Alcaldes pueden imponer a los Concejales por sus faltas de asistencia a las sesiones (artículo 420). Conforme al artículo 240 del Reglamento de Organización, Funcionamiento y Régimen jurídico de las Corporaciones locales de 17 de mayo de 1952, el Alcalde podrá sancionar a los Concejales por negarse a firmar las actas de las sesiones. El artículo 95 del Reglamento de Población de 17 de mayo de 1952, faculta al Alcalde para imponer multas por la negativa de los cabezas de familia a llenar las hojas del padrón de habitantes. etc. $Y$ en numerosas normas legales y reglamentarias se reconoce la potestad sancionadora de los Alcaldes, mediante multa, tanto como Delegado del Gobierno como Jefe de la Administración municipal. En todos estos casos, por tanto, salvo recurso especial, cabe el de alzada ante el Gobernador civil contra el acto del Alcalde por el que imponga un multa.

b) Los actos administrativos de los Alcaldes, sancionadores, mediante multa, históricamente, aun en los momentos de mayor auge autonómico, han sido objeto de recursos de alzada. Así, el artículo 254 del Estatuto municipal de 8 de marzo de 1924 establecía un recurso de alzada ante el Juez de Instrucción.

c) En esta línea el artículo 215 de la Ley del Suelo de 12 de mayo de 1956 no fue una excepción y estableció el recurso de alzada contra las multas impuestas por los Alcaldes, si bien ante la Comisión Provincial de Urbanismo en lugar de ante el Gobernador. Era, pues, uno de los recursos especiales a que se refiere el artículo 385 de la Ley de Régimen local.

La nueva redacción del artículo 225 de la Ley del Suelo, dada por la Ley 19/1975, de 2 de mayo, modifica y revoca, sin duda alguna, los recursos de alzada de los Organismos municipales, frecuentes en la Ley de 1956, en la medida en que atentaban al principio general autonómico del artículo 386 de la Ley de Régimen local. Pero no puede afirmarse lo mismo respecto a las multas que impongan los Alcaldes por infracciones urbanísticas. El artículo 225, reformado, de la Ley del Suelo no dice que todos los actos de las Entidades o autoridades locales causen estado, sino que aquellos 
"que pongan fin a la vía administrativa serán recurribles directamente ante la Jurisdicción Contencioso-administrativa». Luego los que no pongan fin a la vía administrativa no son recurribles directamente a la Jurisdicción Contencioso-administrativa, sino que serán revisables mediante los recursos administrativos legalmente establecidos. Tal es el caso de las multas de los Alcaldes frente a las cuales procede el recurso de alzada ante el Gobernador civil, de conformidad con el artículo 385 de la Ley de Régimen local.

Suprimidos los recursos de alzada contra los actos de las Entidades locales en materia de urbanismo, en general, no existen en la - Ley de Régimen local preceptos conflictivos ni dudosos, salvo en cuanto se refiere a las multas por infracciones urbanísticas, ante la presencia del repetido artículo 385 de la Ley de Régimen local.

No existe en la Ley 19/1975 de Reforma de la del Suelo una expresa derogación de aquel artículo 385 de la Ley de Régimen local. La disposición final 1. ${ }^{a}$ de la Ley 19/1975 deroga «cuantas disposiciones se opongan a lo establecido en esta Ley». Pero, por lo que hemos expuesto, el artículo 225 no se opone al 385 de la Ley de Régimen local.

La novísima Ley 41/1975, de 19 de noviembre, de Bases del Estatuto de Régimen local, tampoco nos resulta ni terminante ni útil para resolver la cuestión. En su Base 41, 4, dispone: «Las resoluciones de las Corporaciones locales agotarán la vía administrativa, salvo que por ley se establezca expresamente un recurso posterior en vía administrativa o económico-administrativa». Con lo cual el problema subsiste, por cuanto sigue admitiendo la posibilidad de recursos en vía administrativa si así lo establece la ley. Por tanto, la materia que nos ocupa tiene esta incómoda, complicada e inútil regulación:

- Los Alcaldes sancionarán con multas las infracciones urbanísticas (artículo 225 bis de la Ley 19/1975 de Reforma de la del Suelo).

- Puede interponerse el recurso de reposición-potestativo, ante el Alcalde, previo al de alzada (artículo 380 de la Ley de Régimen local).

- Contra las multas impuestas por los Alcaldes cabe recurso de alzada ante el Gobernador (artículo 385 de la Ley de Régimen local). 
- Después es cuando quedaría abierto el acceso a la Jurisdicción Contencioso-administrativa (artículos 37, 53 y 58 de la Ley reguladora de la Jurisdicción Contencioso-administrativa de 27 de diciembre de 1956).

Poco se ha ganado, por tanto, en autonomía, en claridad, simplificación y eficacia con la Reforma de la Ley del Suelo, 19/1975, en lo que se refiere, en concreto, a la revisión de los actos sancionadores de los Alcaldes, en materia urbanística, por vía de recursos. La finalidad autonómica proclamada y pretendida por el artículo 220 de la Ley 19/1975, ha resultado, involuntariamente, inconsciente, y descuidadamente mal parada por olvidar, desconocer e ignorar el artículo 385 de la Ley de Régimen local. Es más, mejor dicho, en cierto modo se ha perdido. Nos explicaremos. Recurso de alzada por recurso de alzada nos parece más lógica y conveniente la revisión por la Comisión Provincial de Urbanismo, órgano de competencia específica en materias urbanísticas, que por la autoridad del Gobernador, que ya tiene bastante con sus otras complejas atribuciones y carece de especialización funcional urbanística.

Es necesario, por tanto, que en el desarrollo de la Base 41, 4, del Estatuto de Régimen local, a través del texto articulado del mismo, se salve esta desfavorable y negativa situación, bien generalizando que las multas impuestas por los Alcaldes, en sus atribuciones, causarán estado en la vía gubernativa, o bien semejante norma referida a las multas por infracciones urbanísticas, en aplicación del principio contenido en el artículo 225 de la Ley 19/1975 sobre Reforma de la Ley del Suelo.

\section{CONCLUSIONES}

Primera.-Consideramos que los actos administrativos de los Alcaldes por los cuales imponen sanciones de multa por infracciones urbanísticas, de conformidad con el artículo 215 bis de la Ley 19/1975, de 2 de mayo, que modifica la Ley de Régimen del Suelo y Ordenación urbana de 12 de mayo de 1956, son revisables en recurso de alzada ante el Gobernador civil, en virtud del artículo 385 de la Ley de Régimen local, texto refundido de 24 de junio de 1955. 
Segunda.-El principio general autonómico del artículo 220 de la Ley 19/1975, de 2 de mayo, debe extenderse a las resoluciones de los Alcaldes imponiendo sanciones por infracciones urbanísticas mediante una norma legal que así lo disponga expresamente en el texto articulado de la Ley 41/1975, de 19 de noviembre, de Bases del Estatuto de Régimen local.

Tercera.-De este modo las multas por infracciones urbanísticas impuestas por los Alcaldes seguirán el régimen normal de recursos de los actos administrativos locales: recurso previo de reposición y posteriormente recurso contencioso-administrativo (artículos 37, 52 y 58 de la Ley reguladora de la Jurisdicción Contencioso-administrativa). Así se habrá dado un paso más en el reconocimiento y respeto real a la autonomía municipal. 